\title{
Patient-reported physical activity and the association with health-related quality of life in head and neck cancer survivors
}

\author{
Annette J. van Nieuwenhuizen ${ }^{1}$ - Laurien M. Buffart ${ }^{2,3}$ • Cornelia F. van Uden-Kraan ${ }^{1,4}$. \\ Lilly-Ann van der Velden ${ }^{5,6}$ - Martin Lacko ${ }^{7}$. Johannes Brug ${ }^{2} \cdot$ C. René. Leemans ${ }^{1}$. \\ Irma M. Verdonck-de Leeuw ${ }^{1,4}$
}

Received: 8 March 2017 / Accepted: 9 October 2017 /Published online: 21 November 2017

(C) The Author(s) 2017. This article is an open access publication

\begin{abstract}
Purpose This study aimed to assess patient-reported levels of physical activity (PA) and its associations with health-related quality of life (HRQoL) adjusted for important demographic, lifestyle-related, and clinical factors, among head and neck (HNC) survivors.

Methods This cross-sectional study included 116 HNC survivors. PA was assessed with the Physical Activity Scale for the Elderly (PASE) and HRQoL with the EORTC-QLQ-C30 and EORTC-HN35. Associations were studied using univariable and multivariable regression analyses.

Results Median PASE score was 100.3 (interquartile range $65.1 ; 170.8$ ) of which $54 \%$ were household, 34\% leisure-time, and $12 \%$ occupational activities. Younger HNC survivors had higher levels of PA. Higher PA was significantly associated
\end{abstract}

Irma M. Verdonck-de Leeuw

im.verdonck@vumc.nl

1 Department of Otolaryngology-Head and Neck Surgery, VU University Medical Center, PO BOX 7057, 1007 MB Amsterdam, The Netherlands

2 Department of Epidemiology and Biostatistics, Amsterdam Public Health Research Institute, VU University Medical Center, Amsterdam, The Netherlands

3 Department of Medical Oncology, Cancer Center Amsterdam, VU University Medical Center, Amsterdam, The Netherlands

4 Department of Clinical Psychology, Vrije Universiteit Amsterdam, Amsterdam, The Netherlands

5 Department of Otolaryngology-Head and Neck Surgery, Leiden University Medical Center, Leiden, The Netherlands

6 Department of Head and Neck Oncology and Surgery, Netherlands Cancer Institute, Amsterdam, The Netherlands

7 Department of Otolaryngology-Head and Neck Surgery, University Medical Centre of Maastricht, Maastricht, The Netherlands with higher global QoL $(p<0.05)$. Findings for physical function, role function, social function, fatigue, and pain were in line, but not statistically significant $(0.05 \leq p<0.10)$.

Conclusions Among HNC survivors, a large proportion of PA consists of household activities. Younger HNC survivors had higher PA levels, and higher PA levels were associated with higher HRQoL.

Keywords Head and neck neoplasm · Physical activity · Exercise $\cdot$ Physical functioning $\cdot$ Health-related quality of life

\section{Introduction}

Worldwide, the incidence of head and neck cancer (HNC) has increased over the past decades and 5-year survival rates have improved in Europe [20] and in the USA [29]. As a consequence, more HNC survivors have to cope with physical and psychosocial problems and HNC-specific symptoms associated with cancer and its treatment, such as oral dysfunction, swallowing and speech problems, severely compromising health-related quality of life (HRQoL) [3, 16, 18, 34].

Randomized controlled trials in patients with other types of cancers, mainly breast and prostate cancer, showed that physical activity (PA) can reduce physical and psychosocial problems and improve HRQoL [14, 26, 41]. Observational studies showed that higher levels of moderate-to-vigorous PA are associated with lower mortality risk in survivors of breast, colon, and prostate cancer [19, 21, 25, 30, 38]. Also in HNC survivors, higher pre-treatment levels of PA and physical function were found to be associated with higher HRQoL $[6,36]$ and survival $[10,43]$.

However, PA levels of HNC patients tend to decrease following diagnosis and during treatment [9, 32, 36, 40]. Two 
previous studies $[32,36]$ examined demographic, clinical, and lifestyle correlates of PA and had contradictory results. In a sample of 59 HNC survivors, Rogers et al. [32] found that younger age, the absence of comorbidity, and abstinence from alcohol were related to higher levels of patient-reported PA. Sammut et al. [36] found no associations of gender, smoking, comorbidity, and age with weekly energy expenditure after treatment in a sample of $172 \mathrm{HNC}$ survivors. Insight into demographic and clinical correlates of PA may help to identify which subgroups of HNC survivors are more likely to have low PA.

At present, the number of studies evaluating the associations between PA and HRQoL in patients with HNC is scarce, especially as compared to patients with other types of cancer such as breast or prostate [6]. Furthermore, these studies could only include leisure-time PA and no data on household or occupational activities were included. Rogers et al. [32] found higher levels of leisure-time PA, 18.6 (SD 50.9) months after treatment, to be associated with lower fatigue, higher HRQoL, and higher functional wellbeing after adjusting for age, presence of comorbidities, and alcohol consumption. Sammut et al. [36] reported significant positive correlations between higher levels of PA at 12.9 (SD 12.8) months after treatment and higher HRQoL.

Because of the scarcity of evidence regarding PA levels and the association with HRQoL among HNC survivors, the present study aimed to (1) describe the level of PA among HNC survivors, including leisure-time, household, and occupational PA; (2) study demographic, clinical, and lifestyle-related correlates of PA; and (3) assess the association between PA and HRQoL adjusted for important demographic, clinical, and lifestyle-related factors.

\section{Materials and methods}

\section{Setting and patient recruitment}

In this cross-sectional study, patients were recruited between January and September 2013 from the Departments of Otolaryngology-Head and Neck Surgery from VU University Medical Center, Amsterdam, Leiden University Medical Center, and Maastricht University Medical Center. We included data of PA and HRQoL from two separate studies, the OncoQuest study [11] and the OncoKompas [12] study. At the VU University Medical Center, Amsterdam, the OncoQuest system is implemented as part of standard care, to assess HRQoL in patients with HNC. Additionally, the OncoKompas study was launched, which is an online selfmanagement application where cancer survivors can monitor their HRQoL and get tailored feedback and personalized advice on supportive care services. The HRQoL questionnaires we included for the current study were administered before the online self-management application was carried out. The OncoQuest study and the OncoKompas study included the same HRQoL questionnaires. To be able to answer our research questions on PA in HNC survivors and associations with HRQoL, we added the PASE questionnaire for a limited number of time in both studies. Eligibility criteria and patient recruitment of both studies are presented in Fig. 1. Patients were eligible for this cross-sectional study if they were (1) diagnosed with HNC; (2) treated with surgery, radiotherapy, chemoradiation, or a combination of these treatments; (3) aged 18 years or older; and (4) able to write, read, and speak Dutch. Patients were excluded if they were diagnosed with basal cell carcinomas or lymphoma in the head and neck region, or if they suffered from severe psychiatric comorbidities (e.g., schizophrenia, Korsakov's syndrome, severe dementia). All patients signed an informed consent statement prior to participation. The study was conducted according to regular procedures of the local ethical committee of the VU University Medical Center, Amsterdam.

\section{Outcome measurements}

\section{Physical activity}

PA was assessed with the 13-item Physical Activity Scale for the Elderly (PASE), a self-administered 1-week recall questionnaire on leisure-time, household, and occupational physical activities [44]. The frequency of these activities was recorded as never, seldom (1-2 days a week), sometimes (3-4 days a week), or often (5-7 days a week). The duration of activities was categorized as less than $1 \mathrm{~h}$, between 1 and $2 \mathrm{~h}$, between 2 and $4 \mathrm{~h}$, or more than $4 \mathrm{~h}$. Paid or volunteer work, except for work that involved mostly sitting activities such as office work, was categorized as less than $1 \mathrm{~h}$, between 1 and $4 \mathrm{~h}$, between 5 and

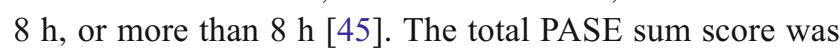
computed by multiplying the amount of time spent on each activity (hours/week) by the empirical derived item weights and summing over all activities [39, 44, 45]. The PASE was shown to have good to excellent test-retest reliability, and good content validity among patients with cancer with an average age of 50 (SD 12). Its construct validity (with accelerometers as comparison measure) was comparable to other PA questionnaires [23].

\section{Health-related quality of life}

HRQoL was assessed with the European Organization for Research and Treatment of Cancer (EORTC), quality of life questionnaire core module (EORTC QLQ-C30), and the tumor-specific HRQoL was assessed by the EORTC head and neck module (EORTC HN35) [4]. The EORTC QLQ-C30 is a 30-item questionnaire including a global QoL scale, five 
Fig. 1 Inclusion flowchart

OncoQuest Study

Aim: Evaluation of a computer assisted data collection system

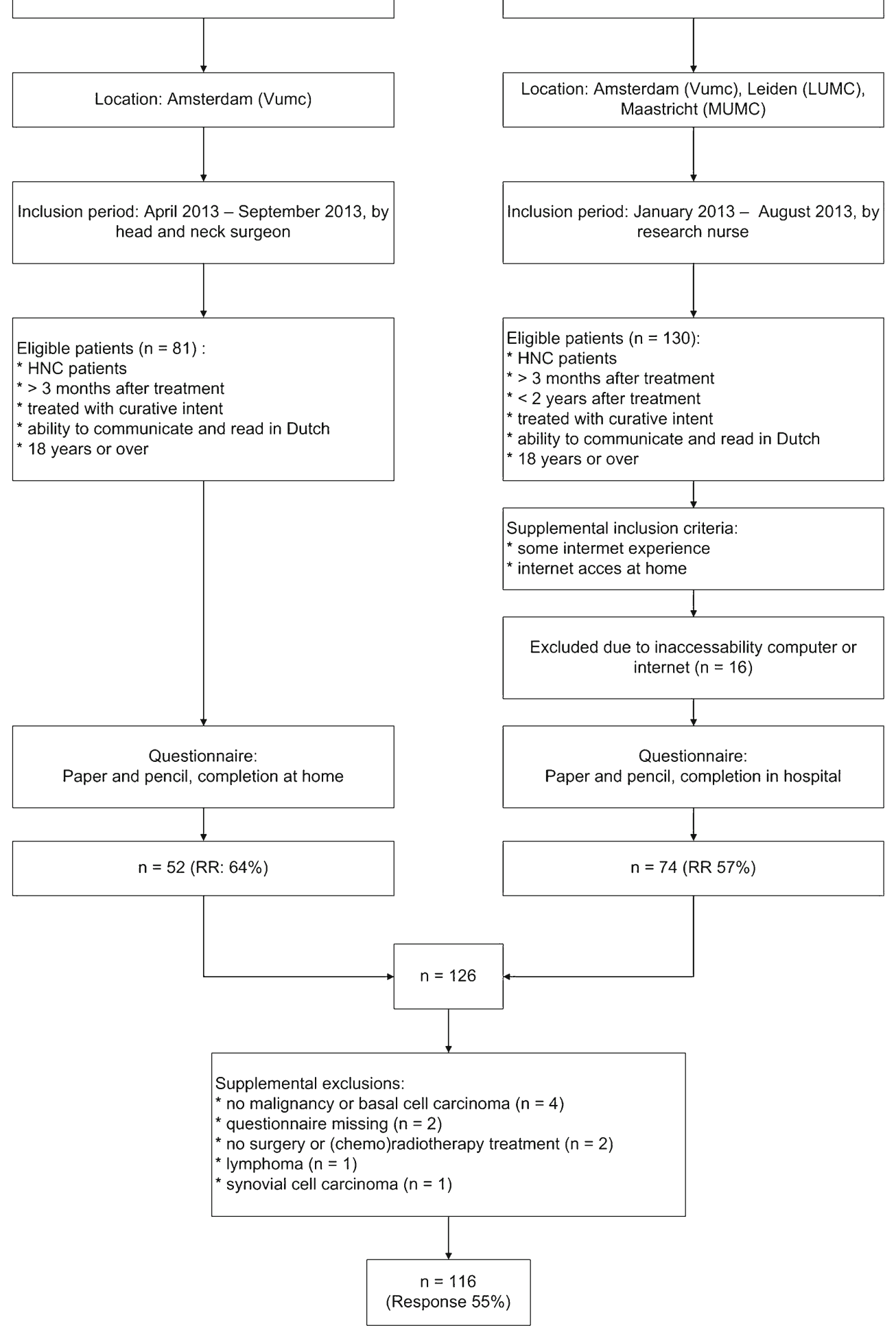

OncoKompas Study

Aim: Evaluation of an internet based e-health application

HNC, head and neck cancer; LUMC, Leiden University Medical Center; MUMC, Maastricht University Medical Center; $\mathrm{n}$, number; PRO, patient-reported outcome; RR, response rate; VUmc, VU University medical center 
function scales, three symptom scales, and six single items, with higher scores presenting higher global QoL and function, and lower scores presenting higher symptom severity [13]. The EORTC HN35 is a 35-item module including HNC-specific symptom scales and 10 single items covering several problems.

\section{Demographic, clinical, and lifestyle-related factors}

Demographic, clinical, and lifestyle-related factors were collected from medical records and included gender, age, zip codes of patients' living area, smoking (pack years, current smoker), alcohol consumption (units per day, current or former abuse ( $\geq 5$ units a day)), tumor site (oral cavity, oropharynx, hypopharynx, larynx, and other), type (squamous cell carcinoma vs. non-squamous cell carcinoma) and stage (I, II, III and IV), tumor recurrence (dichotomized as none vs. any, including local, regional, and second or third primary tumors), treatment modality (surgery, (chemo)radiotherapy, or surgery followed by (chemo)radiotherapy), time since completion of treatment (months), and comorbidities.

Socio-economic status (SES) was determined using zip codes of patients' living area. Zip codes were translated to SES according to The Netherlands Institute for Social Research [1]. This system describes the social status of a district compared to other districts in The Netherlands using an algorithm based on mean income, percentage of people with low income, percentage of people with low education, and percentage of people with without a job. Therefore, the mean score of all districts in The Netherlands is zero. We dichotomized SES scores to high ( $>$ mean value) vs. low ( $\leq$ mean value).

Comorbidities were assessed using the Adult Comorbidity Evaluation 27 (ACE-27), a validated chart built instrument examining the presence of any of the following medical conditions: cardiovascular, respiratory, gastro-intestinal, renal, endocrine, neurological, immunological, previous malignancies, psychiatric disorders, alcohol use, and severe overweight, resulting in a total comorbidity score of none, mild, moderate, or severe [28].

\section{Statistical analysis}

Descriptive statistics (mean, standard deviation (SD), or numbers and percentages) were generated for demographic, lifestylerelated, clinical factors, PA and HRQoL. For the continuous variables, median and interquartile range (IQR) were reported when outcomes were not normally distributed (skewness scores $<-1 ;>1)$. Since total PA score was skewed to the right and the residuals obtained in the regression analysis were not normally distributed, we presented data of total PA as median (IQR) and natural log-transformed the data for analyzing the correlates of PA. We conducted univariable and multivariable linear regression analyses (presenting confidence intervals and standardized regression coefficients) to study demographic, lifestyle-related, and clinical correlates of PA. No multicollinearity ( $r p>0.75$ ) was found. To determine the maximum number of variables to be included in the regression model, we used the rule of thumb of 10 patients per determinant. Consequently, our sample of 116 allowed to include a maximum of 11 variable into the regression model. To prevent overfitting in the multiple linear regression model, we selected variables using a forward selection procedure starting with the variable that most strongly predicted PA. Variables were selected one by one and all variables with $p \leq 0.05$ were inserted in the multiple regression model. We back transformed the results from the final model indicating ratios. The associations between PA and HRQoL were assessed using univariable and multivariable linear regression analyses. For the most accurate estimate of the association, we adjusted for demographic, lifestyle-related, and clinical characteristics. Due to the maximum number of variables allowed in the regression model, we have chosen tumor stage over tumor location and tumor type because it is more strongly associated with quality of life $[3,16,18]$. We explored interactions for the main demographic and clinical characteristics (age, gender, cancer stage, and treatment) to study whether the association between PA and HQoL differed between these subgroups. To limit the number of interactions explored, we tested interactions when the associations between PA and HRQOL had a $p$ value $<0.10$. $P$ values $\leq 0.05$ were considered statistically significant.

\section{Results}

In total, 116 out of $212 \mathrm{HNC}$ survivors met our inclusion criteria and filled out the survey on PA and HRQoL (Fig. 1). Mean (SD) age of participants was 60 (10) years and 63\% were men. The most frequent tumor site was oropharynx (26\%), followed by oral cavity (22\%), larynx (22\%), and hypopharynx (7\%). Most patients were treated by a combination of treatment modalities (58\%). Time since completion of treatment was 21 (21) months. Quality of life scores ranged from 78.2 (global quality of life) to 89.7 (cognitive functioning). Regarding cancer specific HRQoL, symptom scores ranged from 5.1 (social contact) to 24.5 (sexuality, Table 1).

Median (IQR) total PASE score was $100.3(65.1 ; 170.8)$, of which $34 \%$ consisted of leisure-time PA, 54\% of household activities, and $12 \%$ occupational activities. A younger age was significantly associated with higher levels of PA $(\beta=0.98$, $95 \% \mathrm{CI}=0.96 ; 1.00$ ) explaining $5.2 \%$ of the variance in PA (Table 2, 3). No significant associations with PA were found for other demographic, clinical, or lifestyle-related variables.

After adjusting for age, gender, SES, smoking, alcohol abuse, comorbidity, tumor stage, treatment modality, recurrence, and time since treatment, a higher level of PA was significantly associated with higher global QoL ( $\beta$ : 0.06 , $95 \% \mathrm{CI}=0.03 ; 0.10)$. Possible meaningful association were also observed for higher physical function $(\beta: 0.03,95 \%$ $C I=-0.00 ; 0.06)$, role function $(\beta: 0.04,95 \% \mathrm{CI}=-0.00$; 
Table 1 Demographic, lifestyle-related, and clinical characteristics, physical activity (PA), and health-related quality of life (HRQoL)

\begin{tabular}{ll}
\hline Characteristics & $\begin{array}{l}\text { Participants } \\
(n=116)\end{array}$ \\
\hline
\end{tabular}

\section{Demographic factors}

Gender, $n(\%)$ male

Age, mean (SD) years

$60(10)$

SES, mean (SD)

High SES (above average), $n(\%)$

$0.5(0.9)$

Lifestyle-related

Smoking (pack years), median (IQR)

Smoking at diagnosis, $\mathrm{n}(\%)$

Alcohol use (units per day), mean (SD)

Alcohol abuse $^{\mathrm{a}}$ at diagnosis, $\mathrm{n}(\%)$

Clinical factors

Tumor location, $n(\%)$

Oral cavity and oropharynx

$56(48)$

Larynx and hypopharynx

Other $^{\mathrm{b}}$

$33(29)$

$27(23)$

Cancer type, $n(\%)$

Squamous cell

Non-squamous cell

105 (91)

$11(9)$

Disease Stage, $n(\%)$

I and II

III and IV

$75(65)$

Type of treatment, $n(\%)$

Surgery only

Radiotherapy

Chemoradiotherapy

Surgery combined with (chemo)radiation therapy

Recurrence, $n(\%)$

None

Any

Comorbidity, $n(\%)$

None or mild

Moderate or severe

42 (36)

Time since treatment, mediam (IQR) months

$14(7-23)$

Physical activity

Total score, median (IQR)

Leisure-time activities (\% of total PA)

Household activities

Occupational activities

$100.3(65.1-170.8)$

$34 \%$

$54 \%$

$12 \%$

Cancer specific HRQoL, mean (SD)

Global quality of life

$78.2(15.9)$

Physical function

$88.0(13.7)$

$85.5(19.6)$

$85.9(14.0)$

Emotional function

$89.7(14.9)$

$85.6(19.0)$

$23.9(21.5)$

$14.2(19.9)$
Table 1 (continued)

\begin{tabular}{ll}
\hline Characteristics & $\begin{array}{l}\text { Participants } \\
(n=116)\end{array}$ \\
\hline Dyspnea & $14.4(22.9)$ \\
Insomnia & $16.1(35.4)$ \\
Loss of appetite & $6.0(17.9)$ \\
Constipation & $9.2(20.9)$ \\
Diarrhea & $5.2(13.6)$ \\
Financial problems & $9.8(21.1)$ \\
Tumor specific HRQoL, mean (SD) & \\
Pain (mouth) & $17.0(20.9)$ \\
Swallowing & $16.7(23.4)$ \\
Senses & $21.3(23.4)$ \\
Speech problems & $16.4(20.5)$ \\
Social eating & $15.1(22.5)$ \\
Social contact & $5.1(8.9)$ \\
Sexuality & $24.5(29.7)$ \\
Teeth & $13.9(24.2)$ \\
Opening mouth & $13.5(22.4)$ \\
Dry mouth & $42.8(31.3)$ \\
Sticky saliva & $30.4(32.3)$ \\
Coughing & $20.7(27.3)$ \\
Feel ill & $9.8(19.7)$ \\
\hline
\end{tabular}

$C R T$ chemoradiation, $n$ number, $R T$ radiotherapy, $S D$ standard deviation, SES socio-economic status, Surg surgery

${ }^{\text {a }}$ Alcohol abuse defined as $\geq 5$ units of alcohol per day

${ }^{\mathrm{b}}$ Unknown primary, nasopharynx, nasal cavity, nasal sinus, salivary glands, ear, and skin

$0.09)$, social function $(\beta: 0.04,95 \% \mathrm{CI}=-0.00 ; 0.09)$ and lower level of fatigue $(\beta:-0.05,95 \% \mathrm{CI}=-0.10 ; 0.00)$ and less pain $(\beta:-0.04,95 \% \mathrm{CI}=-0.09 ; 0.00)$, but these associations were not statistically significant $(0.05 \leq p<0.10$, Table 4). Explorative analyses showed that gender was a significant effect modifier in the association between PA and general pain $\left(\beta_{\text {interaction }}=-0.09,95 \% \mathrm{CI}=-0.18 ;-0.005\right.$, $p=0.04)$. Explorative stratified analyses for gender revealed a significant association between PA and general pain in women $(\beta=-0.11,95 \% \mathrm{CI}=-0.19 ;-0.03, p=0.01)$, while the association was not statistically significant in men $(\beta=-0.02$, $95 \% \mathrm{CI}=-0.07 ; 0.03, p=0.46$ ). We also found a significant effect modification for age, with a stronger association in patients who were younger $\left(\beta_{\text {interaction }}=0.005,95 \% \mathrm{CI}=0.00\right.$; $0.01, p=0.04)$.

\section{Discussion}

This cross-sectional study describes self-reported PA levels among $\mathrm{HNC}$ survivors, the demographic, lifestyle-related 
Table 2 Demographic, lifestylerelated and clinical correlates of physical activity. Results from univariable regression analyses

\begin{tabular}{llll}
\hline & Ratio $(95 \% \mathrm{CI})$ & $p$ value & Standardized regression coefficients \\
\hline Demographic factors & & & \\
Gender & $1.28(0.93 ; 1.77)$ & 0.13 & 0.14 \\
Age, years & $0.98(0.96 ; 1.00)$ & 0.01 & -0.23 \\
SES & $0.95(0.68 ; 1.34)$ & 0.78 & -0.03 \\
Lifestyle-related factors & & & \\
Smoking, pack years & $1.00(1.00 ; 1.01)$ & 0.32 & 0.09 \\
Smoking at diagnosis & $1.20(0.88 ; 1.64)$ & 0.25 & 0.11 \\
Alcohol, units per day & $0.99(1.07 ; 1.06)$ & 0.79 & 0.02 \\
Alcohol abuse & & & -0.04 \\
Clinical factors & $0.92(0.62 ; 1.36)$ & 0.67 & \\
Tumor location & & & \\
$\quad$ OC and OP & $1.33(0.89 ; 1.98)$ & 0.16 & 0.17 \\
$\quad$ L and HP & $1.22(0.78 ; 1.89)$ & 0.38 & 0.10 \\
$\quad$ Other & Ref & & \\
Cancer type & $1.51(0.88 ; 2.57)$ & 0.13 & 0.14 \\
Disease Stage & $0.98(0.70 ; 1.36)$ & 0.89 & -0.01 \\
Recurrence & $0.69(0.46 ; 1.04)$ & 0.07 & -0.17 \\
Comorbidity & $0.82(0.59 ; 1.14)$ & 0.23 & -0.11 \\
Type of treatment & & & -0.05 \\
$\quad$ Single vs. multiple & $0.92(0.67 ; 1.27)$ & 0.62 & -0.15 \\
Time since treatment (months $)$ & $0.99(0.99 ; 1.00)$ & 0.10 & \\
\hline
\end{tabular}

$C I$ confidence interval, $L$ and $H P$ larynx and hypopharynx, $O C$ and $O P$ oral cavity and oropharynx, Ref reference SES socio-economic status

${ }^{\text {a }}$ Alcohol abuse defined as $\geq 5$ units of alcohol per day

Gender $(0=$ male, $1=$ female $)$, SES $(0=$ other, $1=$ high $)$, current smoking $(0=$ never or former, $1=$ current $)$, alcohol abuse $(0=$ no abuse, $1=$ current or former abuse $)$, cancer type $(0=$ no squamous cell carcinoma, 1 = squamous cell carcinoma), disease stage $(0=$ stage I and II, $1=$ stage III and IV), recurrence $(0=$ no recurrence, $1=$ any recurrence $)$, comorbidity $(0=$ none or mild, $1=$ moderate or severe $)$ and clinical correlates of PA, and the association between PA and HRQoL. Our median PASE score (100.3, IQR 65.1; $170.8)$ was comparable to the HNC population $(n=283)$ in a study from Duffy et al. [9] that reported a mean of 115 pretreatment and a mean of 106 and 110 at 6 and 9 months after treatment, respectively. However, compared to a non-cancer elderly population also using the PASE questionnaire [44], the population of HNC survivors had lower levels of PA (144.9 vs. 100.3). The findings that HNC survivors are at increased risk for low PA levels and the positive association between PA and HRQoL highlight the relevance for evaluating interventions that aim to improve PA levels in this population [37].

In the study, total PA mainly consisted of household activity $(55 \%)$. This is comparable with studies in general populations, reporting that $30-60 \%$ of total PA consists of household activities [8, 27, 44] and this proportion tends to increase with age [27]. Because of their significant contribution to total PA levels, it is important to also assess household and occupational activities, and not just leisure-time PA as is often the case. Also, for interventions aiming to improve PA levels in HNC survivors, it might be useful to focus on promoting PA during daily routines, especially because HNC survivors reported to prefer exercising alone, unsupervised, and at a moderate intensity [33].

Our finding that older HNC survivors are less physically active is in line with previous studies among HNC survivors [32] as well as in survivors of other types of cancer [2, 5, 15]. This illustrates that it is important to promote PA interventions
Table 3 Independent correlates of physical activity. Results of the multivariable regression analyses

\begin{tabular}{llll}
\hline & Ratio $(95 \% \mathrm{CI})$ & $p$ value & Standardized regression coefficients \\
\hline $\begin{array}{l}\text { Demographic factors } \\
\text { Age, years }\end{array}$ & $0.98(0.96 ; 1.00)$ & 0.01 & -0.23 \\
\hline
\end{tabular}

Variables were selected one by one and all variables with $p \leq 0.05$ were inserted in the multiple regression model 
Table 4 The association between physical activity and healthrelated quality of life (HRQoL)

\begin{tabular}{|c|c|c|c|c|}
\hline & Univariable analyses & $p$ value & Multivariable analyses $^{\mathrm{a}}$ & $p$ value \\
\hline HRQoL & $\beta(95 \% \mathrm{CI})$ & & $\beta(95 \% \mathrm{CI})$ & \\
\hline Global quality of life & $0.059(0.025 ; 0.092)$ & 0.01 & $0.061(0.025 ; 0.096)$ & 0.00 \\
\hline Physical function & $0.034(0.004 ; 0.063)$ & 0.03 & $0.027(-0.003 ; 0.057)$ & 0.08 \\
\hline Role functioning & $0.040(-0.003 ; 0.082)$ & 0.07 & $0.044(-0.001 ; 0.089)$ & 0.05 \\
\hline Emotional functioning & $0.011(-0.020 ; 0.042)$ & 0.49 & $0.004(-0.030 ; 0.038)$ & 0.81 \\
\hline Social functioning & $0.034(-0.008 ; 0.075)$ & 0.11 & $0.043(-0.002 ; 0.088)$ & 0.06 \\
\hline Cognitive functioning & $0.019(-0.013 ; 0.052)$ & 0.24 & $0.018(-0.019 ; 0.055)$ & 0.33 \\
\hline Fatigue & $-0.043(-0.090 ; 0.04)$ & 0.07 & $-0.050(-0.103 ; 0.003)$ & 0.06 \\
\hline Nausea and vomiting & $0.000(-0.017 ; 0.017)$ & 0.97 & $-0.004(-0.024 ; 0.015)$ & 0.65 \\
\hline Pain (general) & $-0.050(-0.092 ;-0.007)$ & 0.02 & $-0.044(-0.091 ; 0.003)$ & 0.06 \\
\hline Dyspnoe & $0.013(-0.038 ; 0.063)$ & 0.62 & $0.050(-0.046 ; 0.056)$ & 0.84 \\
\hline Insomnia & $-0.027(-0.083 ; 0.029)$ & 0.34 & $-0.044(-1.05 ; 0.017)$ & 0.15 \\
\hline Loss of appetite & $0.012(-0.027 ; 0.052)$ & 0.54 & $0.001(-0.042 ; 0.045)$ & 0.96 \\
\hline Constipation & $-0.026(-0.072 ; 0.020)$ & 0.27 & $-0.021(-0.072 ; 0.030)$ & 0.42 \\
\hline Diarrhea & $-0.017(-0.046 ; 0.013)$ & 0.27 & $-0.019(-0.053 ; 0.015)$ & 0.28 \\
\hline Financial problems & $0.09(-0.037 ; 0.056)$ & 0.67 & $0.016(-0.036 ; 0.068)$ & 0.54 \\
\hline \multicolumn{5}{|l|}{ Tumor specific HRQoL } \\
\hline Pain (mouth) & $-0.015(-0.061 ; 0.031)$ & 0.53 & $-0.009(-0.060 ; 0.043)$ & 0.74 \\
\hline Swallowing & $-0.022(-0.074 ; 0.029)$ & 0.39 & $-0.022(-0.073 ; 0.029)$ & 0.39 \\
\hline Senses & $-0.028(-0.079 ; 0.024)$ & 0.29 & $-0.019(-0.076 ; 0.038)$ & 0.51 \\
\hline Speech problems & $-0.005(-0.050 ; 0.040)$ & 0.83 & $0.004(-0.045 ; 0.054)$ & 0.86 \\
\hline Social eating & $-0.022(-0.071 ; 0.027)$ & 0.38 & $-0.021(-0.071 ; 0.030)$ & 0.42 \\
\hline Social contact & $-0.008(-0.028 ; 0.012)$ & 0.43 & $-0.005(-0.026 ; 0.017)$ & 0.68 \\
\hline Sexuality & $-0.037(-0.105 ; 0.031)$ & 0.29 & $-0.048(-0.118 ; 0.022)$ & 0.18 \\
\hline Teeth & $0.028(-0.025 ; 0.081)$ & 0.30 & $0.019(-0.039 ; 0.077)$ & 0.51 \\
\hline Opening mouth & $-0.031(-0.080 ; 0.018)$ & 0.21 & $-0.031(-0.084 ; 0.023)$ & 0.26 \\
\hline Dry mouth & $0.009(-0.060 ; 0.078)$ & 0.80 & $0.001(-0.073 ; 0.075)$ & 0.99 \\
\hline Sticky saliva & $0.005(-0.066 ; 0.077)$ & 0.88 & $0.007(-0.069 ; 0.083)$ & 0.86 \\
\hline Coughing & $-0.028(-0.088 ; 0.032)$ & 0.36 & $-0.026(-0.090 ; 0.038)$ & 0.42 \\
\hline Feeling ill & $-0.018(-0.061 ; 0.026)$ & 0.42 & $-0.032(-0.082 ; 0.016)$ & 0.30 \\
\hline
\end{tabular}

${ }^{a}$ Adjusted for age, gender, socio-economic status, smoking, alcohol abuse, comorbidity, tumor stage, treatment, recurrence, and time since treatment in elderly (head and neck) cancer survivors, particularly, because they are at high risk for functional decline after cancer diagnosis [22]. Unfortunately, current interventions to promote PA may not always reach elderly cancer survivors [17]. We found no significant associations regarding PA and other demographic factors (gender and SES) which are comparable to the studies of Rogers et al. [32] and Sammut et al. [36]. However, it should be noted that the information on SES in our study was limited because we estimated SES based on ZIP codes and did not ask patients to provide data on education or income themselves.

In contrast to previous studies, we found no evidence for an association of smoking [5, 15], alcohol consumption [15, 32], or clinical factors with PA $[5,15,31,32]$. The lack of significant associations for clinical factors (e.g., comorbidity, tumor location, and type of treatment) may indicate that the impact of clinical factors reduces over time and other factors such as motivational factors become more important [7, 24, 31, 42]. Future prospective longitudinal studies with objective PA measurements should further clarify whether these associations (demographic, clinical, and lifestyle-related) might be present in HNC survivors or if these are only present during or shortly after treatment.

Our finding that a higher PA level was associated with higher global QoL, and possibly better physical function, role function, social function, and less fatigue and pain among HNC survivors is consistent with previous studies [32, 36]. This indicates that improving PA might be an intervention target to improve HRQoL. However, due to the cross-sectional design, it is not possible to make causal inferences and it is unclear whether improving PA levels would improve HRQoL, or whether HNC survivors with lower HRQoL are less physically active. In 
contrast to general HRQoL, the current study found no support for an association of PA and HNC-specific HRQoL. Due to the cross-sectional nature of this study, it may also suggest that $\mathrm{HNC}$ symptoms are not a barrier to PA. Several small studies have shown that PA interventions among $\mathrm{HNC}$ survivors are feasible and may improve general and HNC-specific HRQoL [6].

Strengths of our study are the relatively large sample size of an understudied group of cancer survivors, allowing to adjust analysis for important demographic, lifestyle-related, and clinical factors. We could also include levels of PA originating from household or occupational activities in addition to leisure-time PA. However, some limitations must be noted. First, the use of a self-reported questionnaire to assess PA levels is susceptible to recall and social desirability bias [35]. This may have led to an overestimation of PA levels, and therefore the absolute PA level should be interpreted with caution. However, the PASE questionnaire is a valid measure to distinguish active from inactive people [23], and therefore the direction of the associations may be considered valid. Second, we assessed lifestyle-related and clinical factors only at diagnosis, and some of these outcomes might have changed at the time (e.g., smoking, alcohol use, comorbidity) of the questionnaire assessment. Third, the lack of associations of PA with clinical factors may be related to the sample size. However, the wide confidence intervals indicate heterogeneity in the association and standardized regression coefficients were small $(\leq 0.23)$, which makes it unlikely that associations will be significant and clinically relevant with larger samples. Finally, the cross-sectional design hampered us to draw conclusions about causality, and future studies are needed to investigate whether increasing PA would improve HRQoL.

In conclusion, in this cross-sectional study we found that HNC survivors, and particularly older survivors, are at risk for low levels of PA. Among HNC survivors, a large proportion of PA consists of household activities. HNC survivors with higher levels of PA had higher global QoL. Future studies should investigate the causality of these associations.

Acknowledgements We would like to thank the participating patients for their contribution to this study. The contributions of AvN, LMB, CFU were funded by grants obtained from the Dutch Cancer Society/Alpe d'HuZes Fund. LMB was funded by a 'Bas Mulder Award, granted by the Dutch Cancer Society.

\section{Compliance with ethical standards}

Conflict of interest All authors declare to have no conflict of interest.

We have full control of all primary data and we agree to allow the journal to review the data if requested.

Open Access This article is distributed under the terms of the Creative Commons Attribution-NonCommercial 4.0 International License (http:// creativecommons.org/licenses/by-nc/4.0/), which permits any noncommercial use, distribution, and reproduction in any medium, provided you give appropriate credit to the original author(s) and the source, provide a link to the Creative Commons license, and indicate if changes were made.

\section{References}

1. (2014) http://www.scp.nl/Onderzoek/Lopend_onderzoek/A_Z alle_lopende_onderzoeken/Statusscores. In: Editor (ed)^(eds) Book http://www.scp.nl/Onderzoek/Lopend_onderzoek/A_Z_ alle_lopende_onderzoeken/Statusscores, City

2. Bauman AE, Reis RS, Sallis JF, Wells JC, Loos RJ, Martin BW (2012) Correlates of physical activity: why are some people physically active and others not? Lancet 380:258-271

3. Bjordal K, Ahlner-Elmqvist M, Hammerlid E, Boysen M, Evensen JF, Biorklund A, Jannert M, Westin T, Kaasa S (2001) A prospective study of quality of life in head and neck cancer patients. Part II: longitudinal data. Laryngoscope 111:1440-1452

4. Bjordal K, Ahlner-Elmqvist M, Tollesson E, Jensen AB, Razavi D, Maher EJ, Kaasa S (1994) Development of a European Organization for Research and Treatment of Cancer (EORTC) questionnaire module to be used in quality of life assessments in head and neck cancer patients. EORTC Quality of Life Study Group. Acta Oncol 33:879-885

5. Buffart LM, Thong MS, Schep G, Chinapaw MJ, Brug J, vdP-F LV (2012) Self-reported physical activity: its correlates and relationship with health-related quality of life in a large cohort of colorectal cancer survivors. PLoS One 7:e36164

6. Capozzi LC, Nishimura KC, McNeely ML, Lau H, Culos-Reed SN (2016) The impact of physical activity on health-related fitness and quality of life for patients with head and neck cancer: a systematic review. Br J Sports Med 50:325-338

7. Courneya KS, Friedenreich CM (1999) Utility of the theory of planned behavior for understanding exercise during breast cancer treatment. Psychooncology 8:112-122

8. Dong L, Block G, Mandel S (2004) Activities contributing to total energy expenditure in the United States: results from the NHAPS study. Int J Behav Nutr Phys Act 1:4

9. Duffy SA, Khan MJ, Ronis DL, Fowler KE, Gruber SB, Wolf GT, Terrell JE (2008) Health behaviors of head and neck cancer patients the first year after diagnosis. Head Neck 30:93-102

10. Duffy SA, Ronis DL, McLean S, Fowler KE, Gruber SB, Wolf GT, Terrell JE (2009) Pretreatment health behaviors predict survival among patients with head and neck squamous cell carcinoma. J Clin Oncol 27:1969-1975

11. Duman-Lubberding S, van Uden-Kraan CF, Jansen F, Witte BI, Eerenstein SEJ, van Weert S, de Bree R, Leemans CR, Verdonckde Leeuw IM (2017) Durable usage of patient-reported outcome measures in clinical practice to monitor health-related quality of life in head and neck cancer patients Support Care Cancer

12. Duman-Lubberding S, van Uden-Kraan CF, Jansen F, Witte BI, van der Velden LA, Lacko M, Cuijpers P, Leemans CR, Verdonck-de Leeuw IM (2016) Feasibility of an eHealth application "OncoKompas" to improve personalized survivorship cancer care. Support Care Cancer 24:2163-2171

13. Fayers P, Bottomley A (2002) Quality of life research within the EORTC-the EORTC QLQ-C30. European Organisation for Research and Treatment of Cancer. Eur J Cancer 38(Suppl 4): S125-S133

14. Ferrer RA, Huedo-Medina TB, Johnson BT, Ryan S, Pescatello LS (2011) Exercise interventions for cancer survivors: a meta-analysis of quality of life outcomes. Ann Behav Med 41:32-47

15. Forbes CC, Blanchard CM, Mummery WK, Courneya KS (2014) A comparison of physical activity correlates across breast, prostate and colorectal cancer survivors in Nova Scotia, Canada. Support Care Cancer 22:891-903

16. Funk GF, Karnell LH, Christensen AJ (2012) Long-term healthrelated quality of life in survivors of head and neck cancer. Arch Otolaryngol Head Neck Surg 138:123-133 
17. Gollhofer SM, Wiskemann J, Schmidt ME, Klassen O, Ulrich CM, Oelmann J, Hof H, Potthoff K, Steindorf K (2015) Factors influencing participation in a randomized controlled resistance exercise intervention study in breast cancer patients during radiotherapy. BMC Cancer 15:186

18. Hammerlid E, Silander E, Hornestam L, Sullivan M (2001) Healthrelated quality of life three years after diagnosis of head and neck cancer - a longitudinal study. Head Neck 23:113-125

19. Holmes MD, Chen WY, Feskanich D, Kroenke CH, Colditz GA (2005) Physical activity and survival after breast cancer diagnosis. JAMA 293:2479-2486

20. Karim-Kos HE, de VE, Soerjomataram I, Lemmens V, Siesling S, Coebergh JW (2008) Recent trends of cancer in Europe: a combined approach of incidence, survival and mortality for 17 cancer sites since the 1990s. Eur J Cancer 44:1345-1389

21. Kenfield SA, Stampfer MJ, Giovannucci E, Chan JM (2011) Physical activity and survival after prostate cancer diagnosis in the health professionals follow-up study. J Clin Oncol 29:726-732

22. Klepin HD, Mohile SG, Mihalko S (2013) Exercise for older cancer patients: feasible and helpful? Interdiscip Top Gerontol 38:146-157

23. Liu RD, Buffart LM, Kersten MJ, Spiering M, Brug J, van MW, Chinapaw MJ (2011) Psychometric properties of two physical activity questionnaires, the AQuAA and the PASE, in cancer patients. BMC Med Res Methodol 11:30

24. Lynch BM, Cerin E, Newman B, Owen N (2007) Physical activity, activity change, and their correlates in a population-based sample of colorectal cancer survivors. Ann Behav Med 34:135-143

25. Meyerhardt JA, Giovannucci EL, Ogino S, Kirkner GJ, Chan AT, Willett W, Fuchs CS (2009) Physical activity and male colorectal cancer survival. Arch Intern Med 169:2102-2108

26. Mishra SI, Scherer RW, Geigle PM, Berlanstein DR, Topaloglu O, Gotay CC, Snyder C (2012) Exercise interventions on healthrelated quality of life for cancer survivors Cochrane Database Syst Rev. CD007566

27. Murphy MH, Donnelly P, Breslin G, Shibli S, Nevill AM (2013) Does doing housework keep you healthy? The contribution of domestic physical activity to meeting current recommendations for health. BMC Public Health 13:966

28. Piccirillo JF, Tierney RM, Costas I, Grove L, Spitznagel EL Jr (2004) Prognostic importance of comorbidity in a hospital-based cancer registry. JAMA 291:2441-2447

29. Pulte D, Brenner H (2010) Changes in survival in head and neck cancers in the late 20th and early 21st century: a period analysis. Oncologist 15:994-1001

30. Richman EL, Kenfield SA, Stampfer MJ, Paciorek A, Carroll PR, Chan JM (2011) Physical activity after diagnosis and risk of prostate cancer progression: data from the cancer of the prostate strategic urologic research endeavor. Cancer Res 71:3889-3895

31. Rogers LQ, Courneya KS, Robbins KT, Malone J, Seiz A, Koch L, Rao K (2008) Physical activity correlates and barriers in head and neck cancer patients. Support Care Cancer 16:19-27
32. Rogers LQ, Courneya KS, Robbins KT, Malone J, Seiz A, Koch L, Rao K, Nagarkar M (2006) Physical activity and quality of life in head and neck cancer survivors. Support Care Cancer 14:10121019

33. Rogers LQ, Malone J, Rao K, Courneya KS, Fogleman A, Tippey A, Markwell SJ, Robbins KT (2009) Exercise preferences among patients with head and neck cancer: prevalence and associations with quality of life, symptom severity, depression, and rural residence. Head Neck 31:994-1005

34. Rogers SN, Ahad SA, Murphy AP (2007) A structured review and theme analysis of papers published on 'quality of life' in head and neck cancer: 2000-2005. Oral Oncol 43:843-868

35. Sallis JF, Haskell WL, Wood PD, Fortmann SP, Rogers T, Blair SN, Paffenbarger RS Jr (1985) Physical activity assessment methodology in the Five-City Project. Am J Epidemiol 121:91-106

36. Sammut L, Fraser LR, Ward MJ, Singh T, Patel NN (2016) Participation in sport and physical activity in head and neck cancer survivors: associations with quality of life. Clin Otolaryngol 41: 241-248

37. Sammut L, Ward M, Patel N (2014) Physical activity and quality of life in head and neck cancer survivors: a literature review. Int J Sports Med 35:794-799

38. Schmitz KH (2011) Exercise for secondary prevention of breast cancer: moving from evidence to changing clinical practice. Cancer Prev Res (Phila) 4:476-480

39. Schuit AJ, Schouten EG, Westerterp KR, Saris WH (1997) Validity of the Physical Activity Scale for the Elderly (PASE): according to energy expenditure assessed by the doubly labeled water method. J Clin Epidemiol 50:541-546

40. Silver HJ, Dietrich MS, Murphy BA (2007) Changes in body mass, energy balance, physical function, and inflammatory state in patients with locally advanced head and neck cancer treated with concurrent chemoradiation after low-dose induction chemotherapy. Head Neck 29:893-900

41. Speck RM, Courneya KS, Masse LC, Duval S, Schmitz KH (2010) An update of controlled physical activity trials in cancer survivors: a systematic review and meta-analysis. J Cancer Surviv 4:87-100

42. Trinh L, Plotnikoff RC, Rhodes RE, North S, Courneya KS (2012) Correlates of physical activity in a population-based sample of kidney cancer survivors: an application of the theory of planned behavior. Int J Behav Nutr Phys Act 9:96

43. van Nieuwenhuizen AJ, Buffart LM, Brug J, Leemans CR, Verdonck-de Leeuw IM (2015) The association between health related quality of life and survival in patients with head and neck cancer: a systematic review. Oral Oncol 51:1-11

44. Washburn RA, McAuley E, Katula J, Mihalko SL, Boileau RA (1999) The physical activity scale for the elderly (PASE): evidence for validity. J Clin Epidemiol 52:643-651

45. Washburn RA, Smith KW, Jette AM, Janney CA (1993) The Physical Activity Scale for the Elderly (PASE): development and evaluation. J Clin Epidemiol 46:153-162 